\title{
BLUEBIRD NESTBOXES: UNUSUAL DESIGNS
}

RONALD A. BITTNER, Box 97, Abernethy, Saskatchewan. SOA OAO

I started operating a bluebird trail in the Abernethy area in 1984, and have been using paired nestboxes since 1988 to reduce competition between Tree Swallows and Mountain Bluebirds. Paired nestboxes have worked well, but I had previously wondered if competition could be reduced through nestbox design. If two styles of boxes were provided, one favoured by bluebirds and one by swallows, this would reduce competition. In order to test the nestbox preferences of swallows and bluebirds, 10 different styles of nestboxes were built. Four were fairly conventional boxes, but with varying dimensions; they will be referred to as standard boxes. The other six were quite unusual in that they had more than one entrance; they will be called test boxes. There have been several boxes of each style used, for a total of 66 . Data will be presented which show that bluebirds have favoured the test boxes, and swallows the standard boxes.

This experiment started with the assumption that standard boxes are the best choice for swallows. Some other design would be sought that would appeal to bluebirds. The considerations that went into the design will now be discussed. Bluebirds have two nesting characteristics which are rarely, if ever, shared by swallows. Firstly, bluebirds do not always nest in a cavity. Occasionally, they select a more open environmental such as a ledge on the exte- rior or interior of a building. Therefore the test boxes were designed to be less confining, by having entrances on two, three or four sides, and by using wide slots instead of round holes. Secondly, bluebirds sometimes choose a nesting site where they must fly upward through an opening to reach the nest. I once observed a bluebird flying upward through a large hole in the soffit of a building, apparently going to a nest. On another occasion, a bluebird nested in a farm implement where it had to fly upward through a 5-inchsquare hole to reach the nest. In the test boxes this factor was approximated by concealing the entrances under the overhanging roof.

The first test boxes were built in 1987. They were remodelled in 1989; the reason will be discussed later. They had entrances on all four sides, and cottage style roofs overhanging the entrances. They are illustrated in the upper half of Figure 1. The corner view shows that the boxes were very open. The sloping roof is omitted for simplicity. The cross section shows how the roof partly concealed the openings. A photograph of one of these boxes appeared in an earlier Blue Jay. ${ }^{1}$ Results with these boxes were encouraging and led to the construction of boxes with three openings and two openings. Most of these boxes were readily accepted by bluebirds.

Nesting results are presented in 


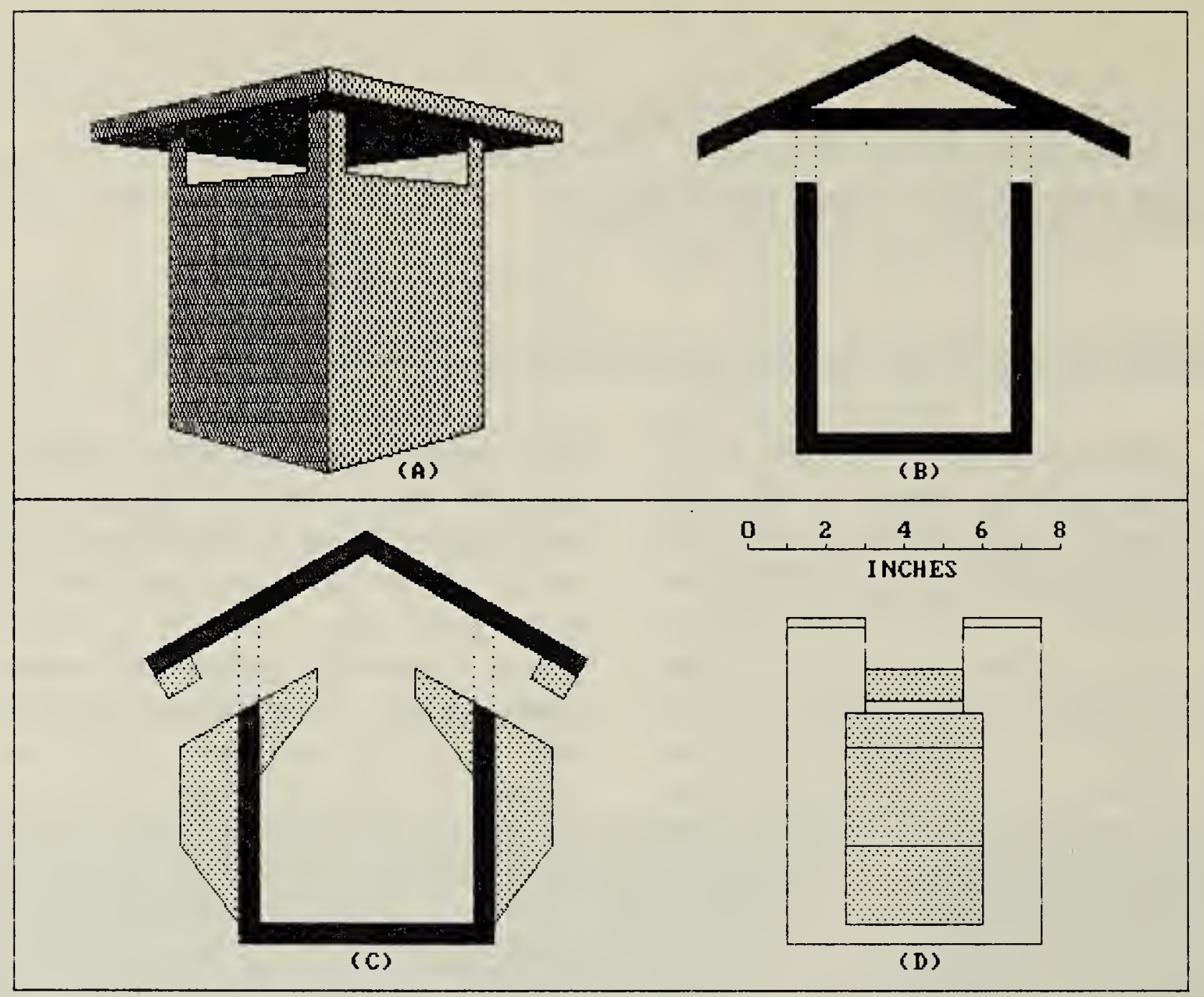

Figure 1. Top: experimental bluebird nestbox with four entrances; (A) corner view without sloping roof; $(B)$ cross section with roof. Bottom: bluebird nestbox with two entrances; (C) front view cross section; (D) side view without roof.

Figure 2. The upper part of the figure shows the 10 nestbox styles. The first four are standard boxes, and the last six are test boxes. The earliest test design is called style 10 in this illustration. The lower part of the figure gives the results. Bluebird occupancy rate is given by the length of the checked bar, and the swallow rate by the length of the striped bar. The white bar represents other species or unused boxes. It can be seen that bluebirds have generally favoured the test boxes and swallows the standard boxes. Do bluebirds like the test boxes because of the extra openings or the concealed openings? This experiment does not provide a definite answer, but suggests that both factors contribute.

The illustrations discussed so far show the boxes as first constructed. They have since been modified at least twice, in an attempt to overcome predation problems. Raccoon predation in 1989 resulted in bluebird and swallow losses of $75 \%$, and in 1990 losses of $50 \%$. It should be noted that losses were equally severe in the standard and test boxes. It was apparent that something should be done to make all the boxes safer. Since this would be a difficult task for boxes with many openings, styles 9 and 10 were converted to two openings from three and four respectively. At the same time, various pieces were added to the inside and outside of all the boxes in the hope that they would prevent raccoons reaching down to the nests. There was no raccoon predation in 1991 and 1992, but it is not known if this was due to the modifications to the boxes or to the lack of raccoon activity. 


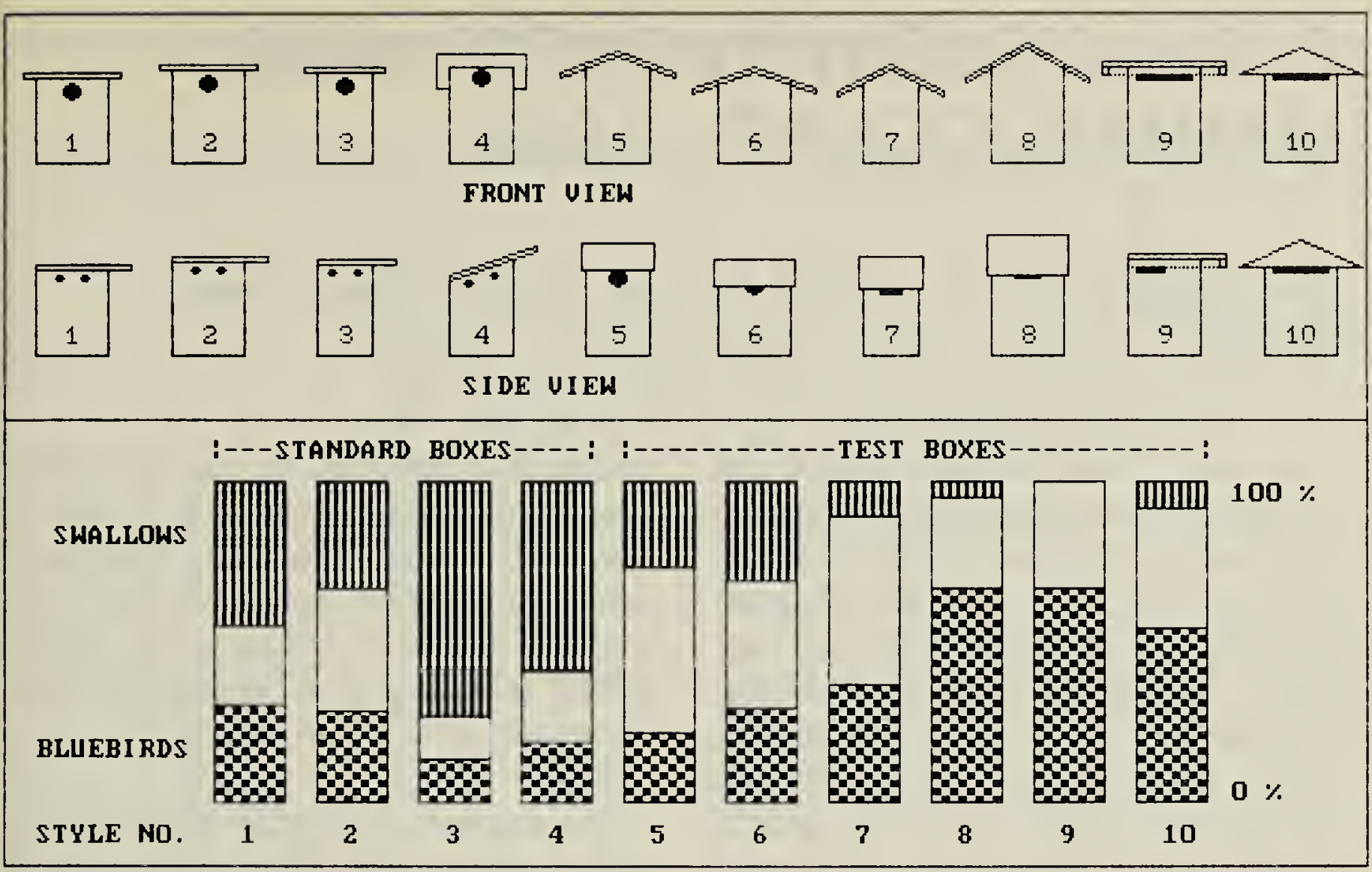

\begin{tabular}{|l|r|r|r|r|r|r|r|r|r|r|r|}
\hline \multicolumn{10}{|c|}{ Nest Box Results } \\
\hline Number of first nestings & 1 & 2 & 3 & 4 & 5 & 6 & 7 & 8 & 9 & 10 & Total \\
\hline Swallows & 27 & 5 & 38 & 17 & 4 & 5 & 2 & 1 & 0 & 2 & 101 \\
Other species \& empty & 15 & 6 & 7 & 6 & 8 & 6 & 9 & 6 & 5 & 7 & 75 \\
Bluebirds & 18 & 4 & 7 & 5 & 3 & 4 & 6 & 13 & 10 & 11 & 81 \\
\hline Total (box-years) & 60 & 15 & 52 & 28 & 15 & 15 & 17 & 20 & 15 & 20 & 257 \\
\hline
\end{tabular}

Figure 2. Bluebird and swallow occupancy rates for 10 nestbox styles, based on 81 bluebird and 101 swallow nestings from 1988 to 1992.

In addition to the box factors discussed so far, two other factors, size and depth, were tested. Size refers to the inside floor dimensions and ranged from 4.5 to 5.5 inches. Depth is the inside measure from the bottom of the entrance to the floor. This ranged from 5.5 to 7.0 inches. Bluebirds have favoured the larger size, and swallows the smaller size. Depth was not a significant factor for either species within the range tested.

One of the most successful test boxes is style 8 . The lower part of Figure 1 shows a box which is similar to the remodelled version of style 8 . Sloping entrance passages are cre- ated by blocks added to the interior and exterior of the side walls. The strips attached to the edges of the roof control the size of the entrances which are 1.25 inches deep. The entrance passages are wide and deep enough to allow easy access by a bluebird once it is past the restriction. The slope and length of the passages might prevent a predator reaching down to a nest. This type of nestbox might interest birders who have tried unsuccessfully to attract bluebirds, or who have experienced raccoon predation in their boxes.

1. BITTNER, R. A. 1988. Bluebirds at Abernethy: history and 1988 results. Blue Jay 46:215-218. 